\title{
When should mechanical circulatory support be considered in pediatric patients with acute fulminant myocarditis?
}

Hye Won Kwon, MD

Department of Thoracic and Cardiovascular Surgery, Seoul National University Children's Hospital, Seoul, Korea

\section{Key message}

Acute fulminant myocarditis is an uncommon syndrome characterized by sudden and severe cardiac inflammation, which leads to cardiogenic shock, ventricular arrhythmia, heart blocks, or multiorgan failure. Despite aggressive clinical course, patients with acute fulminant myocarditis have better outcomes than those with the nonfulminant type when appropriately supported during the acute phase of the disease. Therefore, early recognition of deteriorating myocarditis and timely mechanical circulatory support are crucial to improve outcomes.

In a recent issue of Clinical and Experimental Pediatrics, Heinsar et al. ${ }^{1)}$ presented indications and applications of extracorporeal membrane oxygenation (ECMO) in children with acute fulminant myocarditis (AFM). The authors concluded that ECMO should be considered early as the clinical course of AFM can be unpredictable and lead to rapid hemodynamic collapse. ${ }^{1)}$

AFM is an uncommon syndrome characterized by sudden and severe diffuse cardiac inflammation, which often leads to death due to cardiogenic shock, ventricular arrhythmia, heart blocks, or multiorgan failure. ${ }^{2,3)}$ As AFM is a potentially reversible disease, its early diagnosis and prediction of its progression to a fulminant course are important. However, owing to the broad spectrum of presentation, lack of clear diagnostic criteria, and practice variations, a consensus is difficult to establish for the diagnosis and management of acute myocarditis. ${ }^{4)}$ The gold standard for the diagnosis of myocarditis has been endomyocardial biopsy; however, making the histological diagnosis of AFM is difficult because most children with AFM are extremely sick and hemodynamically unstable. ${ }^{5)}$ Therefore, AFM is often suspected based on the clinical finding of sudden-onset cardiogenic shock in a previously healthy child with symptoms of acute respiratory or gastrointestinal infection and then diagnosed using chest radiography, electrocardiography, echocardiography, and biomarkers such as troponin $\mathrm{T}$ and troponin $\mathrm{I}^{3-5)}$ Inaba et al. ${ }^{6}$ ) suggested systolic hypotension and prolonged QRS on admission as predictors of a fulminant course of myocarditis. Wu et al. ${ }^{7)}$ suggested that female sex, vomiting, weakness, seizure, arrhythmia, a left ventricular ejection fraction (LVEF) of $<60 \%$ on echocardiography, and initial serum troponin I cutoff values of $>14.21 \mathrm{ng} / \mathrm{mL}$ predict the need for ECMO. As the authors emphasized, early recognition of these clinical signs of a failing heart is critical for improving the outcomes of AFM. 1,6,7)

In the management of AFM, initial stabilization requires hemodynamic and respiratory support to maintain adequate tissue perfusion and end-organ oxygen delivery. ${ }^{2)}$ If the patient is refractory to conventional therapy with inotropic support and mechanical ventilation, ECMO should be considered as a bridge to recovery or transplantation. ${ }^{1,5)}$ Indications for ECMO in AFM are progressive severe cardiogenic shock refractory to medical treatment, life-threatening ventricular arrhythmia, multiorgan failure, and cardiac arrest. ${ }^{5,8)}$ Duncan et al. ${ }^{9}$ ) suggested that an increase in inotropic requirements, accompanied by evidence of inadequate cardiac output such as poor cutaneous perfusion, oliguria, and systemic acidosis, is unlikely to be reversed by further medical management. More practically, $\mathrm{Hsu}$ et al. ${ }^{8)}$ suggested that for profound and rapidly progressive ventricular dysfunction with persistent low blood pressure (systolic blood pressure $<60 \mathrm{mmHg}$ for children and $<50 \mathrm{mmHg}$ for infants) measured by arterial lines and oliguria $(<0.5 \mathrm{~mL} / \mathrm{kg} / \mathrm{hr})$ under inotropic equivalents (IE; $\mu \mathrm{g} / \mathrm{kg} / \mathrm{min}=$ dopamine + dobutamine $+100 \times$ epinephrine $+100 \times$ norepinephrine $+100 \times$ isoproter enol $+15 \times$ milrinone) of $>40 \mu \mathrm{g} / \mathrm{kg} / \mathrm{min}$, ECMO implantation should be considered.

Despite having a more aggressive clinical course, patients with AFM had better outcomes in terms of recovery of ventricular function and atrioventricular conduction than those with the non-fulminant type when successfully supported during the acute phase of the disease. ${ }^{9,10)}$ Although randomized controlled trials evaluating the use of ECMO in AFM have been rarely conducted, the survival-to-discharge rate was reported to range from $64 \%$ to $83 \%$ in a case series of patients with AFM who received ECMO support. ${ }^{5,8,9)}$

In addition to the timing of ECMO initiation, the decision to wean from ECMO is also important for avoiding complications that may arise during its use for extended periods of time. If

\footnotetext{
Corresponding author: Hye Won Kwon, MD. Department of Thoracic and Cardiovascular Surgery, Seoul National University Children's Hospital, 101 Daehak-ro, Jongno-gu, Seoul 03080, Korea 
the patient with AFM shows recovery of cardiac function and stable hemodynamics, weaning of ECMO may be considered. The suggested criteria for ECMO weaning were an improved LVEF $(>30 \%)$ and an IE $<20 \mu \mathrm{g} / \mathrm{kg} / \mathrm{min}$ with acceptable hemodynamics. ${ }^{8)}$

In conclusion, early suspicion of AFM is important in patients with symptoms of nonspecific viral infections if they show any symptoms and signs of decreased systemic perfusion. ECMO may provide acceptable survival rates in patients with AFM. Early recognition of deteriorating acute myocarditis and the availability of timely mechanical circulatory support are crucial to improve outcomes.

\section{Conflicts of Interest}

No potential conflicts of interest relevant to this article are reported.

See the article "The use of extracorporeal membrane oxygenation in children with acute fulminant myocarditis" via https:// doi.org/10.3345/cep.2020.00836.

\section{References}

1. Heinsar S RS, Suen JY, Cho HJ, Fraser JF. The use of extracorporeal membrane oxygenation in children with acute fulminant myocarditis. Clin Exp Pediatr 2021;64:188-95.

2. Kociol RD, Cooper LT, Fang JC, Moslehi JJ, Pang PS, Sabe MA, et al. Recognition and initial management of fulminant myocarditis: a scientific statement from the American Heart Association. Circulation 2020;141:e69-92.

3. Cooper LT Jr. Myocarditis. New Engl J Med 2009;360:1526-38.

4. Ghelani SJ, Spaeder MC, Pastor W, Spurney CF, Klugman D. Demographics, trends, and outcomes in pediatric acute myocarditis in the United States, 2006 to 2011. Circ Cardiovasc Qual Outcomes 2012;5:622-7.

5. Nahum E, Dagan O, Lev A, Shukrun G, Amir G, Frenkel G, et al. Favorable outcome of pediatric fulminant myocarditis supported by extracorporeal membranous oxygenation. Pediatr Cardiol 2010;31:1059-63.

6. Inaba O, Satoh Y, Isobe M, Yamamoto T, Nagao K, Takayama M. Factors and values at admission that predict a fulminant course of acute myocarditis: data from Tokyo CCU network database. Heart Vessels 2017;32:952-9.

7. Wu HP, Lin MJ, Yang WC, Wu KH, Chen CY. Predictors of extracorporeal membrane oxygenation support for children with acute myocarditis. Biomed Res Int 2017;2017:2510695.

8. Hsu KH, Chi NH, Yu HY, Wang CH, Huang SC, Wang SS, et al. Extracorporeal membranous oxygenation support for acute fulminant myocarditis: analysis of a single center's experience. Eur J Cardiothorac Surg 2011;40:682-8.

9. Duncan BW, Bohn DJ, Atz AM, French JW, Laussen PC, Wessel DL. Mechanical circulatory support for the treatment of children with acute fulminant myocarditis. J Thorac Cardiovasc Surg 2001;122:440-8.

10. Lin KM, Li MH, Hsieh KS, Kuo HC, Cheng MC, Sheu JJ, et al. Impact of extracorporeal membrane oxygenation on acute fulminant myocarditisrelated hemodynamic compromise arrhythmia in children. Pediatr Neonatol 2016;57:480-7.

How to cite this article: Kwon HW. When should mechanical circulatory support be considered in pediatric patients with acute fulminant myocarditis? Clin Exp Pediatr 2021;64:227-8. https:// doi.org/10.3345/cep.2020.01165 